\title{
Benedito Borges da Silva
}

\author{
Gil Facina
}

Professor Benedito Borges da Silva, MD, PhD, was born on March 20, 1950. Graduated in Medicine at Universidade Federal do Piauí (UFPI) in 1976. He completed his Doctorate in Medicine (Gynecology) at Universidade Federal de São Paulo (UNIFESP) in 1997, and Post-doctorate at Universidade Estadual de Campinas (UNICAMP) (2002). He was a Full Professor of the Maternal and Child Department (Gynecology) at the UFPI and worked for their Voluntary Service Program during his postgraduate studies. He was a master's and doctoral advisor at the Graduate Program in Science and Health of UFPI and in Biotechnology (Graduate Program in Biodiversity, PPGB) in the Northeast Biotechnology Network (RENORBIO). He was a 1B Research Productivity Fellow and Ad Hoc Consultant to the National Council for Scientific and Technological Development (CNPq), a founding member of the Piauí Academy of Sciences (2002), and President of the Piauí Society of Gynecology and Obstetrics (1991-1993). Executive Coordinator of the Medical Residency Program at the Health Sciences Center (CCS) at UFPI (1997-1999). Coordinator of the discipline of Gynecology at UFPI (2001-2015). Head of the CCS Maternal and Child Department (2000-2002). Coordinator of the Gynecology Clinic at Hospital Getúlio Vargas (HGV) (2001-2013). Coordinator of the Interinstitutional Master's at UFPI-UNICAMP (2000-2003). Director-General of the Getúlio Vargas Hospital, in Teresina, Piauí (2003). Coordinator of Medical Residency in Mastology at UFPI (2005-2014). President of the Research and Bioethics Commission of the Brazilian School of Mastology (2011-2013). Member of the National Specialized Committee on Mastology of FEBRASGO (2012-2015). Coordinator of the Master's in Science and Health (2009-2010 and 2012-2016). PhD coordinator, member of the Scientific Committee and leader of a study and research group in Gynecological and Breast Oncology

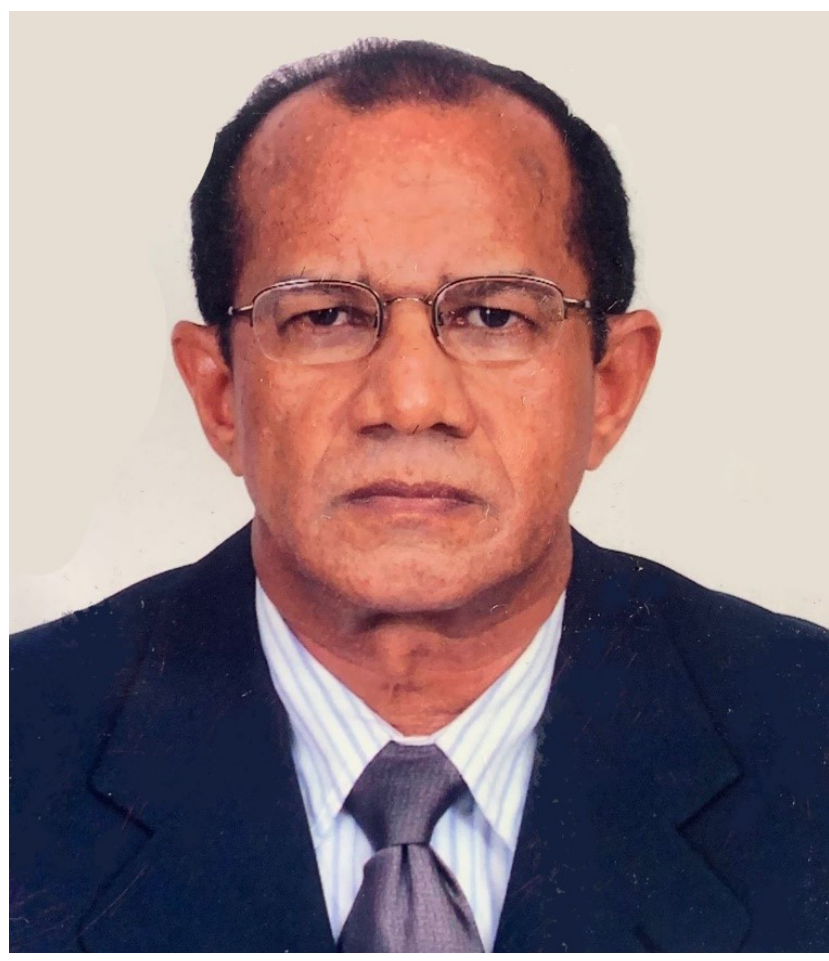

at RENORBIO, Ponto Focal Piauí (2007-2010). He has published over 100 full-length articles in indexed international journals, and has three computer programs registered with the National Institute of Industrial Property. He has also been the advisor of 121 works, being 49 masters, 14 doctorates, 43 scientific initiations, 7 specializations and 8 of a different nature. He has acted in Medicine with an emphasis on Gynecology and Mastology, and passed away of complications from COVID-19 on September 6,2021.

${ }^{1}$ Universidade Federal de São Paulo - São Paulo (SP), Brazil. 